\title{
Postoperative anaemia and acute kidney injury: a retrospective study in major orthopedic surgery
}

Antunes P., Muchacho P., Resende A.

Centro Hospitalar de Lisboa Norte - Hospital de Santa Maria, Dept of Anaesthesiology \& Pain Medicine, Lisbon, Portugal

\section{BACKGROUND AND GOAL OF THE STUDY}

Acute kidney injury has been correlated with perioperative anaemia possibly due to less oxygen transport capacity. ${ }^{1}$ The aim of this study was to examine the association between postoperative anaemia and acute kidney injury in major orthopedic surgery.

\section{MATERIALS AND METHODS}

Retrospective analisys, with Local Ethics Committee approval. Patients submitted to elective orthopedic surgery.

Exclusion criteria: minor surgery, chronic kidney disease under haemodialysis, serum creatinine $>1.6 \mathrm{mg} / \mathrm{dL}$ for $\mathrm{men}$ and $>1.4 \mathrm{mg} / \mathrm{dL}$ for women, intraoperative mean arterial pressure $<55 \mathrm{mmHg}$ and incomplete records.

AKI was defined as an increment of baseline serum creatinine of $>0.3 \mathrm{mg} / \mathrm{dL}$ or $>50 \%$ within $48 \mathrm{~h}$ (AKI Network).

Anaemia was considered for haemoglobin levels $<10.0 \mathrm{~g} / \mathrm{dL}$.

Statistic analysis: SPSS ${ }^{\circledR}$ V21.0 (Chi-square, Fisher Exact and Mann-Whitney U tests); a simple binary logistic regression was performed to identify independent factors for acute kidney injury; $p<0.05)$.

RESULTS

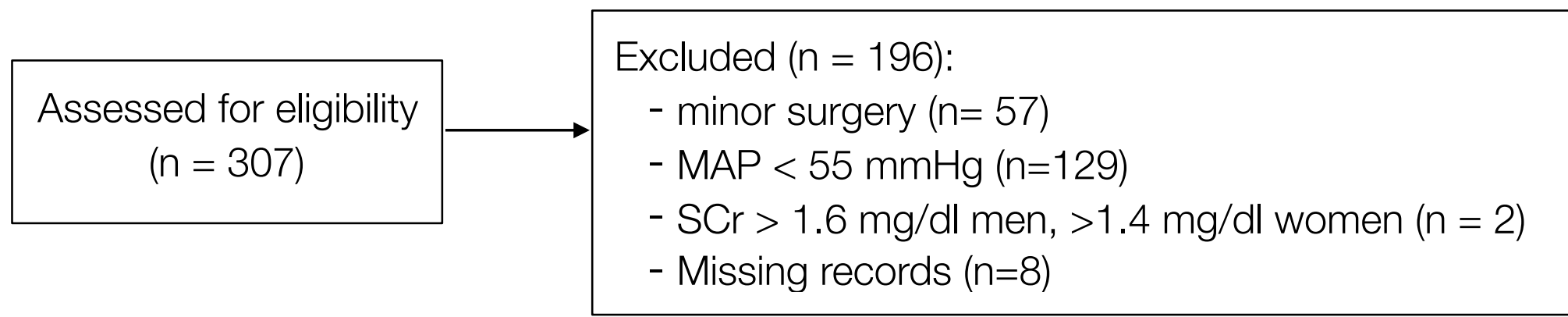

Study group $(n=111)$

Patients characteristics and perioperative data

\begin{tabular}{|c|c|c|c|c|}
\hline Variables & Total $(n=111)$ & $\mathrm{Hb}<10(\mathrm{n}=46)$ & $\mathrm{Hb}>10(n=65)$ & $p$ value \\
\hline Age (years) & $60.95 \pm 17.56$ & $65.57 \pm 16.28$ & $57.69 \pm 17,82$ & 0,019 \\
\hline Gender $\left(\partial^{\lambda}:+\right)^{\prime}$ & 52 (46.8):59 (53.2) & $18(39.1): 28(60.9)$ & $34(52.3): 31(47,7)$ & 0,171 \\
\hline $\mathrm{BMI}\left(\mathrm{kg} / \mathrm{m}^{2}\right)$ & $27.70 \pm 4.95$ & $26,94 \pm 5,14$ & $28.23 \pm 4.79$ & 0,179 \\
\hline Hypertension & $61(55.0)$ & $29(63.0)$ & $32(49.2)$ & 0,150 \\
\hline Diabetes mellitus & $20(18.0)$ & $10(21.7)$ & $10(15.4)$ & 0,391 \\
\hline Ischemic heart disease & $8(7.2)$ & $5(10.9)$ & $3(4.6)$ & 0,272 \\
\hline Chronic kidney disease & $5(4.5)$ & $5(10.9)$ & $0(0)$ & 0,011 \\
\hline Serum albumin $(g / d L)$ & $3.25 \pm 0.51$ & $3.03 \pm 0.50$ & $3.41 \pm 0.46$ & $<0,001$ \\
\hline Serum creatine before surgery $(\mathrm{mg} / \mathrm{dL})$ & $0.86 \pm 0.29$ & $0.87 \pm 0.38$ & $0.85 \pm 0.19$ & 0,369 \\
\hline \multicolumn{5}{|l|}{ Type of anaesthesia: } \\
\hline General & $45(40.5)$ & $16(34.8)$ & $29(44.6)$ & \multirow{2}{*}{0,299} \\
\hline Neuroaxial & $66(59.5)$ & $30(65.2)$ & $36(55.4)$ & \\
\hline Duration of surgery (minutes) & $140 \pm 74$ & $155 \pm 83$ & $130 \pm 66$ & 0,078 \\
\hline Hemoglobin at 48 hours & $10.8 \pm 1.9$ & $9.04 \pm 0.83$ & $12.06 \pm 1.49$ & $<0,001$ \\
\hline AKI at 48 hours & $6(5.4)$ & $4(8.7)$ & $2(3.1)$ & 0,23 \\
\hline
\end{tabular}

Data are expressed as the mean \pm SD or number (\%). BMI, Body Mass Index

Proportion of patients with acute kidney injury within 48 hours

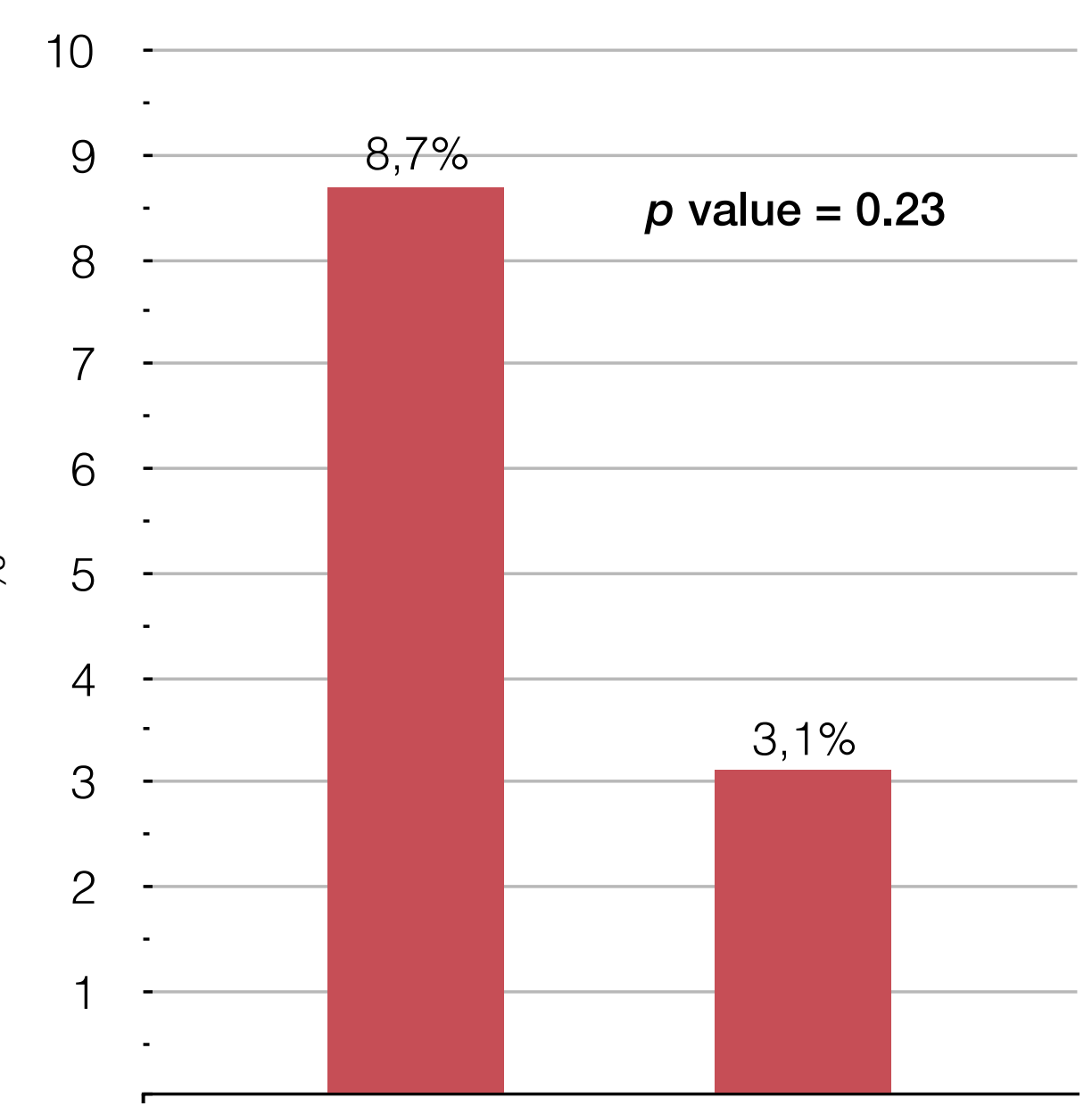

$\mathrm{Hb}<10$

$\mathrm{Hb}>10$
Simple binary logistic regression - Risk factor for acute kidney injury

\begin{tabular}{lcc}
\hline Variable & OR $(\mathrm{Cl} \mathrm{95 \% )}$ & $p$ value \\
\hline Age & $1.11(1.00-1.23)$ & 0,04 \\
\hline
\end{tabular}

\section{CONCLUSION}

A statistically significant association between postoperative anaemia and acute kidney injury was not established. Increasing age was independently associated with an increased likelihood of exhibiting acute kidney injury.

It would be necessary a large and controlled prospective study in order to clarify this tendencies. 